\title{
Percepção do consumismo dos portugueses na época de Natal
}

\author{
EULÁLIA SANTOS 1 \\ FERNANDO OLIVEIRA TAVARES ${ }^{2}$
}

${ }^{1}$ Instituto Politécnico de Leiria / Escola Superior de Tecnologia e Gestão (ESTG), Leiria - Portugal

${ }^{2}$ Instituto Superior de Ciências Empresariais e do Turismo (ISCET), Porto Portugal

\section{Resumo}

A presente investigação tem como objetivo analisar o consumo estimado pelos portugueses na época de Natal. O Natal transporta em si uma contradição, por ser considerado um feriado religioso mas também uma das ocasiões mais consumistas e lucrativas para o mundo cristão. Utilizou-se uma metodologia quantitativa baseada num questionário, onde os inquiridos, para além de responderem a um conjunto de questões de índole sociodemográfica, indicaram com quem passariam a festividade. Indicaram também o valor a gastar em presentes para oferecer e em bens de consumo na época de Natal. A amostra é constituída por 1.077 indivíduos portugueses, maiores de 18 anos. Os resultados demonstram que esses indivíduos estimam gastar mais em presentes para oferecer do que em bens de consumo. Verifica-se também que o consumo estimado para essa época do ano aumenta com a idade, com o número de elementos do agregado familiar, com o nível de escolaridade e com o rendimento mensal do agregado familiar. Os indivíduos que estimam gastar mais na época de Natal são: homens; os que têm religião; os que possuem familiar direto com menos de 16 anos; e os que são casados ou vivem em união de fato. O estudo ajuda a perceber as motivações do consumo na época natalina e a sua importância no desenvolvimento econômico. Espera-se que este estudo venha a contribuir para desvendar o espírito de Natal e expor o simbolismo presente nas variadas manifestações sociais e culturais da sociedade. Palavras-chave: Natal. Consumo. Materialismo. Afetividade familiar. Mercado de Natal. 


\title{
Consumerism perception in Portugal at Christmas time
}

\begin{abstract}
The research analyzes the estimated consumption at Christmas time in Portugal. Christmas is a religious holiday and also one of the most consumerist and profitable occasions in Christian countries, which may be considered a contradiction. A quantitative methodology based on a questionnaire was used, where participants answered a set of sociodemographic questions and indicated with whom they would spend the next Christmas. They also indicated the estimated amount they will spend on gifts and consumer goods. The sample consists of 1,077 Portuguese individuals over 18 years old. The results show that Portuguese individuals expect to spend more on gifts than on other consumer goods. In addition, the estimated consumption over the Christmas holidays increases with age, the number of people in the household, level of education, and monthly household income. Individuals who estimate spending more are men, religious people, individuals who have a direct family member under the age of 16, married people (or those with a long-term partner). The study helps to understand the motivations of consumption at Christmas time and its importance in economic development. Finally, the research intends to contribute to unravel the spirit of Christmas and expose the symbolism present in society's social and cultural expressions.

KeYwords: Christmas. Consumption. Materialism. Family Affectivity. Christmas Market.
\end{abstract}

\section{Percepción del consumismo portugués en la temporada navideña}

\section{Resumen}

La presente investigación tiene como objetivo analizar el consumo estimado por los portugueses en Navidad. La Navidad conlleva una contradicción, ya que es al mismo tiempo una fiesta religiosa y una de las ocasiones más consumistas y rentables para el mundo cristiano. Se utilizó una metodología cuantitativa basada en un cuestionario, en el que los encuestados además de responder un conjunto de preguntas de carácter sociodemográfico e indicar con quién pasarían la próxima Navidad, también informaron la cantidad estimada que gastarían en regalos y en bienes de consumo en la época navideña. La muestra constó de 1.077 individuos portugueses mayores de 18 años. Los resultados demostraron que los portugueses estiman gastar más en regalos que en bienes de consumo. También se verificó que el consumo estimado para esa época aumenta con la edad, con el número de miembros de la familia, con el nivel de educación y con el ingreso mensual del hogar. Las personas que estiman gastar más en Navidad son: hombres; los que tienen religión; los que tienen un familiar directo menor de 16 años; y los casados o parejas de hecho. El estudio ayuda a comprender las motivaciones del consumo en Navidad y su importancia en el desarrollo económico. Se espera que este estudio contribuya a desvelar el espíritu navideño y exponer el simbolismo presente en las variadas manifestaciones sociales y culturales de la sociedad. Palabras Clave: Navidad. Consumo. Materialismo. Afectividad familiar. Mercado navideño. 


\section{INTRODUÇÃO}

O Natal é a festa da família, das crianças e do consumismo. Hoje existe um Natal religioso e um Natal consumista, apesar de a religião rejeitar o materialismo. O Natal é constituído por uma variedade de práticas e rituais diferenciados entre culturas. No caso de Portugal, a celebração envolve festa em família, troca de prendas, envio de mensagens, decorações especiais típicas dessa época do ano, entre outros costumes. Percebe-se que a data tem um forte simbolismo e tem sido usado como uma grande oportunidade para o aumento da procura de bens e serviços.

Embora, por excelência, seja a festa da família, das crianças, dos amigos, da generosidade, do relaxar e desfrutar da atmosfera do Natal, há também quem aproveite para viajar para locais paradisíacos, num claro corte com a rotina quotidiana.

No entanto, no entender de Cruz (2013), o nascimento de Jesus divide a história do mundo e dos homens em duas partes: o antes e o depois. Nos dias que correm o Natal está a transformar-se numa festa laica, onde por vezes a família já nem se reúne. Existe um crescente desaparecimento do religioso (CRUZ, 2013).

A data de 25 de dezembro é coincidente com o solstício de inverno no calendário romano e justifica-se pelo sincretismo entre o cristianismo e os cultos solar de Mitras e do Sol Invictus no império romano (ROQUE, 2013). Assim, Cruz (2013) entende que o Natal cristão batizou uma festa pagã ao longo do tempo, e espiritualidade e mundanidade estiveram sempre associados.

$\mathrm{Na}$ literatura, não se encontram muitos estudos relacionados com o Natal. Em particular, existe uma carência de estudos que relacionem o Natal com a área da administração. O consumo está relacionado em termos de economia com o rendimento disponível das famílias. Esse rendimento, em Portugal, de acordo com a Pordata (2020), aumentou de 2014 (29.245,5 euros) até 2018 (33.196,0 euros), mas continua inferior à média europeia. Assim, considera-se pertinente a realização do presente estudo.

Este artigo tem como objetivo analisar o consumo estimado pelos portugueses na época de Natal. Para concretizar esse objetivo, para além desta introdução, o artigo apresenta em seguida a revisão da literatura. Na terceira seção é exposta a metodologia, onde se começa por apresentar a população e a amostra, os instrumentos de recolha de dados e os procedimentos levados em consideração na realização do trabalho de investigação. $\mathrm{Na}$ quarta seção são apresentados os resultados e a sua discussão. É também analisado o consumo e o endividamento na época de Natal, e são testadas as hipóteses de investigação. No final do artigo, são apresentadas as conclusões.

\section{REVISÃO DE LITERATURA}

A celebração do Natal carrega em si um paradoxo, por ser considerado um proeminente feriado religioso e uma das ocasiões mais lucrativas para o mundo cristão. Há quem inclua também o mundo não cristão, uma vez que, graças à influência da hegemonia norte-americana e à popularidade da figura mítica do Papai Noel, a data também proporciona aumento nas vendas em países onde o cristianismo não é a religião maioritária (BATINGA, PINTO e RESENDE, 2017). Robinot, Ertz e Durit (2017) referem que a atmosfera de Natal leva as pessoas a consumir mais nessa fase do ano, e que elas necessitam mudar sua atitude para se comportar de forma racional e responsável. 
No entender de Clarke (2007), o Natal assumiu em todo o mundo relevância em termos de consumo, tornando-se num momento em que as pessoas gastam de forma mais livre, espontânea e generosa em aspectos ligados à sua preparação e seu desfrute.

É reconhecido que o materialismo e o consumismo intensificam-se nessa época do ano, o que é um paradoxo com o espírito natalino, uma vez que a religião cristã rejeita o materialismo (DEACY, 2016). Isso é visível durante a época de Natal, uma vez que os centros comerciais e as lojas de rua aumentam suas vendas. Segundo Batinga, Pinto e Resende (2017), o materialismo é entendido como a importância que o consumidor atribui às posses mundanas, que conferem status, distinção e poder. O consumismo é o ato de consumir, por vezes desmedido.

O Natal enquadra-nos como sujeitos religiosos, porque assim tem sido difundido na América (BURROUGHS, 2019). Hoje há um capitalismo religioso e o Natal é mais que um feriado cristão, é um feriado consumista secular. Os aspectos favoritos do Natal são a reunião de família, as tradições, as festas e a comida. O Natal serve para algumas funções, como ensinar às crianças a importância de doar, incentivar a compaixão e o amor ao próximo.

Para Ribeiro (2018), a religião cristã é colocada como uma forma de vida que pode inverter o quadro caótico da cultura consumista. A autora questiona se será a cultura consumista que está imersa no cristianismo ou se será o cristianismo que está imerso na cultura consumista. Schuster, Dias e Battistella (2016) entendem que, no consumismo, embora exista diferenças em nível de gênero, elas não são significativas, isto é, o modelo de mensuração não as detecta. Simões e Amaral (2018) concluem que quanto mais elevada é a escolaridade, maior é o rendimento das famílias, e maior a tendência para o consumo. Referem que investir na educação é um degrau para erradicar as desigualdades e melhorar as condições de vida das pessoas. É normal nas famílias de maior rendimento haver uma maior tendência para o consumo (BARR, 2020).

Miller (2017) refere que o Natal é uma festa vivida intensamente nas famílias. É tradição oferecer presentes aos familiares e amigos. As pessoas oferecem presentes porque se permitem expressar, de forma vincada, sua identidade (ROBINOT, ERTZ e DURIT, 2017). Dyble, Van Leeuwen e Dunbar (2015) concluíram que no Natal os entrevistados compravam presentes de maior valor para familiares próximos e indivíduos de suas relações sociais. Embora homens e mulheres gastem quantias semelhantes em presentes para parentes e pessoas das relações sociais próximas, há uma grande diferença no que é gasto com amigos e relações sociais distantes entre gêneros, gastando as mulheres significativamente mais. Ganassali (2019) concluiu que crianças e jovens vivem intensamente o Natal. Nas cartas que escrevem ao Papai Noel há quatro tipo de mensagens: gourmet (refletem o desejo de pedir um único presente, normalmente caro); gulosices (sweet tooth); brinquedos; e rebuçados de marca.

Segundo um estudo da Deloitte (2018), os principais fatores que incentivam a despesa durante as festividades de Natal são as promoções e o fato de os europeus, em geral, quererem se divertir sem pensar na situação econômica. Essa consultoria refere ainda que Portugal é um dos países da Europa que mais afirmam gastar do seu orçamento de Natal e Ano Novo, em datas especiais como a Black Friday. O estudo refere ainda que no topo das prendas em Portugal estão os chocolates e os livros, mas existem diferenças de gênero (homens recebem mais alimentação e bebidas e mulheres perfumes). Ainda segundo o estudo, os portugueses privilegiam as compras nos centros comerciais, seguindo-se pela ordem de preferência os hipermercados ou supermercados, as lojas de rua, os retalhistas especializados, os outlets e as lojas de luxo. Os 
portugueses preferem fazer os pagamentos em dinheiro, por cartão de débito, recorrendo uma pequena parte ao cartão de crédito.

No entender de Tavares, Pacheco e Sousa (2014), a procura de centros comerciais está relacionada com sete fatores: a publicidade; os níveis de consumismo; a praça de restauração; o cinema; a higiene e segurança do centro comercial; o acesso a produtos e bens de tecnologia; e a existência de hipermercado no centro comercial.

Segundo outro estudo efetuado pela Deloitte (2019), o mercado on-line tem vindo a crescer em Portugal e prevê-se que possa vir a representar 25\% das compras de Natal. Apesar dessa tendência crescente, as famílias portuguesas continuam a eleger as lojas físicas como locais preferenciais de compra de prendas devido ao serviço personalizado de atendimento, às políticas de devolução e a uma maior confiança no método de pagamento utilizado. Ainda nesse estudo é referido que a primeira quinzena de dezembro é o período eleito para fazer as compras de Natal, havendo uma tendência para antecipar para novembro, tendo impacto nessas compras o período de Black Friday.

Cunha, Tavares e Durão (2019) concluem que o principal atributo das redes sociais é a proximidade com o cliente e o contato permanente que potencializa o relacionamento entre a empresa e os consumidores. As marcas utilizam as redes sociais como plataformas privilegiadas de comunicação $\mathrm{B} 2 \mathrm{C}$, valorizando a transmissão rápida das mensagens e a facilidade em interagir e receber feedbacks dos fãs e consumidores.

Brida, Meleddu e Tokarchuk (2017) referem que os principais motivos na comemoração do Natal é passar tempo com a família e os amigos, relaxar e apreciar a atmosfera de Natal. Entendem também que o Natal tem o potencial de influenciar positivamente a cultura, o desenvolvimento econômico e fomentar o turismo numa época baixa. Esse mercado turístico de Natal cria, além de impactos econômicos, um valor de conhecimento para a comunidade anfitriã, que se beneficia do intercâmbio cultural trazido pelos turistas e da revitalização urbana durante a época baixa.

Brida, Disegna e Osti (2013), ao estudarem três mercados turísticos no período de Natal no norte de Itália, concluíram que o objetivo da viagem, a região de origem, a percepção do evento, o tempo de permanência e a idade são fatores significativos que influenciam a propensão para o consumo e a quantidade de dinheiro gasta durante as visitas.

Com base nos objetivos definidos e na revisão da literatura efetuada no presente estudo, formularam-se as hipóteses de investigação listadas a seguir, acompanhadas com a respetiva fundamentação teórica que serão testadas na parte empírica.

- Hipótese 1: A estimativa do valor a gastar em presentes para oferecer é superior à estimativa do valor a gastar em bens de consumo na época de Natal.

- Os estudos efetuados pela consultora Deloitte em 2018 e 2019 concluíram que os portugueses e os europeus estimam gastar mais em presentes comparativamente a bens de alimentação.

- Hipótese 2: Existe relação positiva entre a idade e o consumo estimado para a época de Natal.

Robinot, Ertz e Durif (2017) registram que na época de Natal as pessoas consomem mais, sendo naturalmente esperado, que com o aumento da idade e do rendimento disponível, aumente também o consumo. 
- Hipótese 3: Existe relação positiva entre o número de elementos do agregado familiar e o consumo estimado para a época de Natal.

- Segundo Miller (2017), as famílias vivem intensamente o Natal, sendo esperado que o consumo aumente nos agregados familiares de maior número de elementos.

- Hipótese 4: Existe relação positiva entre os níveis de escolaridade e o consumo estimado para a época de Natal.

- Simões e Amaral (2018) mencionam que quanto mais elevada a escolaridade, maior tenderá a ser o rendimento familiar, e maior a tendência para o consumo.

- Hipótese 5: Existe relação positiva entre os rendimentos mensais do agregado familiar e o consumo estimado para a época de Natal.

- Barr (2020) refere que as famílias com maior rendimento apresentam uma tendência para maior consumo.

- Hipótese 6: Existem diferenças no consumo estimado na época de Natal entre os homens e as mulheres.

- Schuster, Dias e Battistella (2016) registram que, embora existam diferenças no consumo em relação ao gênero, elas não são estatisticamente significativas.

- Hipótese 7: Os indivíduos que têm familiar direto com menos de 16 anos estimam gastar mais na época de Natal.

- Ganassali (2019) concluiu que as crianças e os jovens vivem intensamente o Natal, sendo assim esperado que as famílias com crianças e jovens gastem mais no Natal.

- Hipótese 8: Existem diferenças no consumo estimado na época de Natal entre os diferentes estados civis.

Dyble, Leeuwen e Bunbar (2018) concluíram que no Natal as pessoas compram presentes de maior valor para familiares próximos e indivíduos das suas relações sociais próximas.

- Hipótese 9: Existem diferenças no consumo estimado na época de Natal entre os indivíduos da religião cristã, os ateus e os das restantes religiões.

- Ribeiro (2018) refere que a cultura cristã está ligada (hoje confundindo-se) com o consumismo.

- Hipótese 10: Existem diferenças no consumo na época de Natal entre as várias regiões de Portugal.

- Estudos efetuados pela consultora Deloitte em 2018 e 2019 referem que existem diferenças nos padrões de consumo nas várias regiões de Portugal (DELOITTE, 2018, 2019).

\section{METODOLOGIA}

\section{População e amostra}

A população-alvo do presente estudo são os portugueses maiores de 18 anos. Para efetuar a recolha de dados, recorreu-se ao método não aleatório de amostragem por conveniência devido à facilidade de acesso aos elementos da amostra e ao baixo custo associado.

Após a aplicação dos questionários, apenas foram considerados para análise 1.077 indivíduos com idades compreendidas entre 18 e 73 anos, sendo a média de aproximadamente 36 anos 
$(S D=12,37)$. A maioria dos indivíduos é do sexo feminino $(56,3 \%, n=606)$. No que respeita ao nível de escolaridade, $47,5 \%(n=512)$ têm licenciatura, 25,6\% $(n=276)$ têm o $12^{\circ}$ ano, 22,5\% ( $n=242)$ têm mestrado ou doutoramento, e 4,4\% $(n=47)$ têm até o $9^{\circ}$ ano. Quanto ao estado civil, 46,1\% $(n=496)$ são indivíduos solteiros, $44,9 \%(n=484)$ são casados ou vivem em união de fato, e os restantes $9 \%(n=97)$ são separados, divorciados ou viúvos.

O número de elementos do agregado familiar varia de 1 a 9 , sendo a média de aproximadamente 3 elementos $(S D=1,31)$, e a maioria não possui familiar direto com menos de $16 \operatorname{anos}(60,4 \%, n=651)$. No que concerne ao rendimento mensal do agregado familiar, tem-se que $41,1 \%(n=443)$ recebem de 1.001 a 2.000 euros, $24 \%(n=258)$ recebem de 2.001 a 3.000 euros, $17,5 \%(n=189)$ recebem mais de 3.000 euros e $17,4 \%(n=187)$ recebem até 1.000 euros.

Relativamente à religião, tem-se que $87,1 \%(n=938)$ são cristãos, 9,6\% $(n=103)$ indicam ser ateus e 3,3\% $(n=136)$ dizem ser de outras religiões.

Agruparam-se os diferentes distritos de Portugal em cinco regiões, sendo que 27,6\% ( $n=297)$ dos indivíduos são da região Norte (Braga, Bragança, Porto, Viana do Castelo e Vila Real), 44,8\% ( $n=482$ ) são da região Centro (Aveiro, Castelo Branco, Coimbra, Guarda, Leiria e Viseu), 9,6\% ( $n=103$ ) são da região de Lisboa (Lisboa e Setúbal), 15,2\% ( $n=164)$ são da região do Alentejo (Beja, Évora, Portalegre e Santarém) e 2,9\% $(n=31)$ são da região do Algarve (Faro).

A esmagadora maioria dos indivíduos $(96,3 \%, n=1.037)$ indica que passa o Natal com a família, 12 (1,1\%) indicam passar o Natal sozinhos, 11 (1\%) com amigos, 11 (1\%) com colegas de trabalho, $3(0,3 \%)$ com família e amigos, $2(0,2 \%)$ com vizinhos e $1(0,1 \%)$ não comemora o Natal.

\section{Instrumentos de recolha de dados}

A metodologia empregada na presente investigação é quantitativa, sendo o instrumento utilizado um inquérito por questionário, constituído por quatro partes. Na primeira parte, os inquiridos indicam com quem vão passar o Natal de 2019 e se possuem ou não familiares dependentes com menos de 16 anos. A segunda parte questiona os inquiridos sobre o valor que estimam gastar em presentes para oferecer e em bens de consumo no Natal de 2019. A terceira parte analisa a importância atribuída aos locais de compra, a aspectos relacionados com promoções (promoções e descontos, atendimento, opções de pagamento, facilidade de acesso à loja e sorteio de prêmios) e aos diferentes momentos festivos da época natalícia: noite de Natal (do dia 24 para o dia 25 de dezembro), dia de Natal (dia 25 de dezembro), passagem do ano (do dia 31 de dezembro para o dia $1^{\circ}$ de janeiro) e Dia de Reis (dia 6 de janeiro). A quarta e última parte analisa o perfil sociodemográfico dos inquiridos: sexo, idade, nível de escolaridade, estado civil, religião, número de elementos do agregado familiar, rendimento mensal do agregado familiar e distrito de residência. 


\section{PROCEDIMENTOS}

Os questionários foram aplicados a indivíduos portugueses maiores de 18 anos, entre os dias $1^{\circ}$ e 23 de dezembro de 2019. Foram apresentados aos participantes acompanhados de um pequeno resumo introdutório definindo os objetivos do estudo e garantindo o anonimato e a confidencialidade das informações prestadas.

Para efetuar a análise dos dados, recorreu-seao software IBMSPSS Statistics 25, e utilizaram-se as técnicas de estatística descritiva para detalhar a amostra e para efetuar a análise descritiva de algumas variáveis que caracterizam o consumo estimado para a época de Natal.

Utilizou-se a técnica de inferência estatística para comparar médias entre grupos e estudar a relação entre variáveis. Para a análise das diferenças de médias entre o valor estimado a gastar em presentes para oferecer e o valor estimado a gastar em bens de consumo, usou-se o teste $t$ de Student para amostras emparelhadas. Para a análise das diferenças de médias entre grupos independentes aplicou-se o teste $t$ de Student ou a Analysis of Variance (ANOVA), dependendo se a comparação estabelecida era entre dois ou três grupos. Sempre que foram encontradas diferenças significativas a partir da ANOVA, utilizou-se o teste de comparação múltipla de Tukey (HAIR, BLACK, BABI et al., 2014; MARÔCO, 2018; PESTANA e GAGEIRO, 2014).

Para calcular o tamanho do efeito das diferenças das médias dos grupos usou-se o eta quadrado de Cohen, que representa a proporção de variação da variável dependente que é explicada pela variável independente. Segundo Pallant (2013), os valores do eta quadrado de Cohen podem ser classificados como: 0,01 (efeito pequeno), 0,06 (efeito moderado) e 0,14 (efeito grande).

No sentido de averiguar a existência de relações entre as variáveis, recorreu-se à correlação de Pearson e de Spearman. De um modo geral, nas ciências sociais e humanas, considerase a magnitude das correlações: i) fraca, quando; ii) moderada, quando; iii) forte, quando; e iv) muito forte, quando (MARÔCO, 2018).

Realça-se que os pressupostos estatísticos para a aplicação dos diferentes testes foram analisados previamente, o que permitiu a sua aplicação com confiança.

\section{RESULTADOS E DISCUSSÃO}

\section{Consumo e endividamento na época de Natal}

Os 1.077 inquiridos que responderam ao questionário estimaram gastar, em média, aproximadamente 418 euros $(S D=409,47)$ na época de Natal, onde se estima que 249 euros $(S D=260,82)$ em média sejam gastos em presentes para oferecer e 169 euros $(S D=199,68)$ sejam gastos em bens de consumo. Os valores obtidos neste estudo são um pouco superiores aos obtidos no estudo de Natal realizado com a participação de 786 portugueses pela consultoria Deloitte, em 2019, onde cada família portuguesa previa gastar em média 387 euros (9 euros a mais do que no estudo de Natal da mesma consultoria relativamente a 2018), e situa-se abaixo da média europeia, que é de 461 euros (DELOITTE, 2018, 2019).

No sentido de analisar se os 1.077 inquiridos se endividam na época de Natal, comparou-se o consumo estimado com o rendimento mensal do agregado familiar. Na Tabela 1, apresentam-se os consumos médios estimados por rendimento mensal do agregado familiar, verificando-se 
que os consumos médios estimados se encontram enquadrados dentro dos rendimentos mensais do agregado familiar, não mostrando evidências de endividamento. Efetuando uma análise em maior pormenor, verificou-se que apenas 3 (0,3\%) indivíduos apresentam evidências para o endividamento, pois estimam gastar mais na época de Natal do que o rendimento mensal do agregado familiar. Note-se que os inquiridos não atribuem muita importância às opções de pagamento em prestações $(M=1,96, S D=1,22)$.

\section{TABELA 1}

Consumos médios estimados para a época de natal por rendimento mensal do agregado familiar

\begin{tabular}{|c|c|c|c|c|}
\hline & & Presentes & Bens & Total \\
\hline \multirow{2}{*}{ Até 1.000 euros $(n=187)$} & $M$ & 134,52 & 112,14 & 246,66 \\
\hline & SD & 105,78 & 135,33 & 207,18 \\
\hline \multirow{2}{*}{ De 1.001 a 2.000 euros $(n=443)$} & $M$ & 197,71 & 133,70 & 331,41 \\
\hline & SD & 146,94 & 135,78 & 239,63 \\
\hline \multirow{2}{*}{ De 2.001 a 3.000 euros $(n=258)$} & $M$ & 299,26 & 190,87 & 490,14 \\
\hline & SD & 276,93 & 183,36 & 410,68 \\
\hline \multirow{2}{*}{ Mais de 3.000 euros $(n=189)$} & $M$ & 413,39 & 279,10 & 692,48 \\
\hline & SD & 415,68 & 319,03 & 649,50 \\
\hline
\end{tabular}

Fonte: Elaborada pelos autores.

$\mathrm{Na}$ amostra em estudo, verifica-se que os indivíduos atribuem bastante importância à promoção de preços $(M=3,90, S D=1,19)$, atendimento $(M=3,87, S D=1,10)$, desconto no preço à vista $(M=3,76, S D=1,24)$ e facilidade de acesso à loja $(M=3,70, S D=1,23)$.

No que respeita aos locais de compra, os indivíduos preferem lojas de rua próximas da sua residência $(M=3,67, S D=1,17)$, centros comerciais ou shoppings $(M=3,55, S D=1,23)$ e supermercados $(M=3,40, S D=1,19)$. Às lojas on-line via computador $(M=2,92, S D=1,35) \mathrm{e}$ m-commerce via smartphone ou tablet $(M=2,62, S D=1,31)$ os indivíduos atribuem níveis mais baixos de importância. Isso está de acordo com os estudos efetuados pela consultoria Deloitte (2019).

\section{Testar hipóteses}

Por meio da aplicação do teste $t$ de Student para amostras emparelhadas verificou-se que o valor estimado a gastar em presentes para oferecer difere estatisticamente do valor estimado a gastar em bens de consumo na época de Natal $(t(1,076)=11,93, p<0,001)$. A magnitude das diferenças médias apresenta um tamanho de efeito grande $(=0,12)$. Assim, pode-se inferir que os indivíduos portugueses estimam gastar mais em presentes para oferecer $(M=248,92$, $S D=260,82)$ do que em bens de consumo $(M=169,17, S D=199,68)$, o que suporta empiricamente a Hipótese 1, corroborando com os resultados dos estudos efetuados em Portugal (DELOITTE, 2018, 2019). Realça-se também que, a partir da correlação de Pearson, se verifica que existe uma 
relação positiva e estatisticamente significativa entre o valor estimado a gastar em presentes para oferecer e o valor a gastar em bens de consumo $(r=0,57, p<0,001)$, sendo a correlação classificada de forte, o que significa que quanto maior é o valor que se estima gastar em presentes para oferecer, maior será o valor estimado a gastar em bens de consumo. Tudo isso confirma que no Natal as pessoas consomem mais (ROBINOT, ERTZ e DURIT, 2017), o que faz com que nessa época do ano as pessoas gastem de forma livre e espontânea (CLARKE, 2007).

Da aplicação da correlação de Pearson (Tabela 2) verifica-se que existe relação estatisticamente significativa e positiva de magnitude moderada entre a idade e o valor do consumo estimado para a época de Natal $(p<0,001)$ e de magnitude fraca entre o número de elementos do agregado familiar e o valor do consumo estimado para a época de Natal $(p<0,05)$. De acordo com a aplicação da correlação de Spearman (Tabela 2), verifica-se que existe relação estatisticamente significativa e positiva de magnitude fraca entre os níveis de escolaridade e o valor do consumo estimado para a época de Natal $(p<0,001)$ e de magnitude moderada entre os rendimentos mensais do agregado familiar e o valor do consumo estimado para a época de Natal $(p<0,001)$. Assim, pode-se inferir que o consumo estimado para a época de Natal aumenta com a idade, com o número de elementos do agregado familiar, com o nível de escolaridade e com o rendimento mensal do agregado familiar. Isso suporta empiricamente as Hipóteses 2, 3, 4 e 5, corroborando com os resultados dos estudos de Robinot, Ertz e Durif (2017), que afirmam que na época de Natal o consumo é maior; de Miller (2017), que considera que as pessoas vivem o Natal de forma intensa, o que poderá aumentar o consumo nas famílias com maior número de elementos; e de Simões e Amaral (2018), que concluíram que os indivíduos com maior nível de escolaridade apresentam uma maior tendência para o consumo, sendo consequência de um maior rendimento (BARR, 2020).

TABELA 2

Correlação de pearson e de spearman

\begin{tabular}{lcccc} 
Consumo & Correlação de Pearson & \multicolumn{2}{c}{ Correlação de Spearman } \\
Idade & $\begin{array}{r}\text { Número de } \\
\text { elementos } \\
\text { do agregado } \\
\text { familiar }\end{array}$ & $\begin{array}{c}\text { Nível de } \\
\text { escolaridade }\end{array}$ & $\begin{array}{c}\text { Rendimento } \\
\text { mensal do } \\
\text { agregado } \\
\text { familiar }\end{array}$ \\
\hline Presentes & $0,26^{* * *}$ & $0,06^{*}$ & $0,20^{* * *}$ & $0,37^{* * *}$ \\
\hline Bens & $0,26^{* * *}$ & $0,07^{*}$ & $0,12^{* * *}$ & $0,28^{* * *}$ \\
\hline Total & $0,30^{* * *}$ & $0,07^{*}$ & $0,19^{* * *}$ & $0,37^{* * *}$ \\
\hline
\end{tabular}

Nota: ${ }^{* * *} p<0,001,{ }^{*} p<0,05$.

Fonte: Elaborada pelos autores.

$\mathrm{Na}$ Tabela 3, apresentam-se os dados relativos à aplicação do teste $t$ de Student para amostras independentes, para comparar o consumo estimado entre homens e mulheres, verificando-se a existência de diferenças estatisticamente significativas $(p<0,05)$. Os homens estimam gastar mais na época de Natal, o que suporta empiricamente a Hipótese 6, corroborando com os resultados do estudo de Schuster, Dias e Battistella (2016), que verificaram a existência de diferenças no consumo em nível de gênero, embora não significativas. Note-se que neste estudo, embora as diferenças sejam estatisticamente significativas, a magnitude das diferenças médias, segundo Pallant (2013), apresenta um tamanho de efeito pequeno $\left(\eta^{2}=0,01\right)$. 
TABELA 3

Comparação do consumo estimado na época de natal entre homens e mulheres

\begin{tabular}{lcccccc} 
& \multicolumn{7}{c}{ Sexo } & & $\begin{array}{c}\text { Tamanho } \\
\text { do efeito }\end{array}$ \\
Consumo & $M$ & SD & $M$ & SD & $t$ & \\
\hline Presentes & 272,41 & 302,27 & 230,66 & 221,89 & $2,52^{*}$ & 0,01 \\
\hline Bens & 196,52 & 241,46 & 147,90 & 156,80 & $3,79^{* * *}$ & 0,01 \\
\hline Total & 468,94 & 485,07 & 378,56 & 334,41 & $3,46^{* *}$ & 0,01 \\
\hline
\end{tabular}

Nota: $" * p<0,001, " * p<0,01, " p<0,05$.

Fonte: Elaborada pelos autores.

A partir da Tabela 4, verificou-se a existência de diferenças estatisticamente significativas no consumo estimado na época de Natal entre os indivíduos que possuem um familiar direto com menos de 16 anos e os que não possuem $(p<0,01)$. Os indivíduos que possuem familiar direto com menos de 16 anos são os que estimam gastar mais na época de Natal, o que vai ao encontro do estudo de Dyble, Van Leeuwen e Dunbar (2015), que consideram que no Natal as pessoas compram presentes de maior valor para familiares próximos e indivíduos das suas relações sociais. Isso é o esperado, de acordo com Ganassali (2019), pois as crianças e os jovens vivem intensamente o Natal, o que faz com que as famílias com crianças e jovens (com menos de 16 anos) gastem mais nessa época do ano. Assim, a Hipótese 7 é suportada empiricamente. No entanto, a magnitude das diferenças médias, segundo Pallant (2013), apresenta um tamanho de efeito pequeno.

\section{TABELA 4}

Comparação do consumo estimado na época de natal entre os que possuem ou não familiar direto com menos de 16 anos

\begin{tabular}{|c|c|c|c|c|c|c|}
\hline \multirow{3}{*}{ Consumo } & \multicolumn{4}{|c|}{ Possuir familiar direto com menos de 16 anos } & \multirow{3}{*}{$\begin{array}{c}\text { Teste } \\
t\end{array}$} & \multirow{3}{*}{$\begin{array}{l}\text { Tamanhc } \\
\text { de efeito }\end{array}$} \\
\hline & \multicolumn{2}{|c|}{ Não $(n=651)$} & \multicolumn{2}{|c|}{$\operatorname{Sim}(n=426)$} & & \\
\hline & $M$ & SD & $M$ & SD & & \\
\hline Presentes & 219,48 & 205,61 & 293,91 & 322,81 & $-4,23^{* * *}$ & 0,02 \\
\hline Bens & 152,86 & 167,08 & 194,09 & 239,21 & $-3,10^{* *}$ & 0,01 \\
\hline Total & 372,33 & 322,79 & 488,00 & 506,98 & $-4,19^{* * *}$ & 0,02 \\
\hline
\end{tabular}

Nota: ${ }^{* * *} p<0,001,{ }^{* *} p<0,01$.

Fonte: Elaborada pelos autores.

O teste de Levene não revelou a homogeneidade de variâncias, o que levou à aplicação do teste de Welch (Tabela 5), verificando-se a existência de diferenças significativas no consumo estimado na época de Natal entre os diferentes estados civis $(p<0,001)$. Por meio do teste de comparações múltiplas de Games-Howell, foram verificadas diferenças significativas entre os indivíduos solteiros e os casados ou que vivem em união de fato $(p<0,001)$ e entre os indivíduos solteiros e os separados, divorciados e viúvos $(p<0,01)$. Os casados ou os que vivem em união de fato são os que estimam gastar mais na época de Natal. Assim, suporta-se empiricamente 
a Hipótese 8, o que seria o esperado, pois, de acordo com os resultados do estudo de Dyble, Leeuwen e Bunbar (2018), no Natal as pessoas compram presentes de maior valor para familiares próximos e indivíduos das suas relações sociais próximas.

TABELA 5

Comparação do consumo estimado na época de natal entre os diferentes estados civis

\begin{tabular}{|c|c|c|c|c|c|c|c|}
\hline \multirow{3}{*}{ Consumo } & \multicolumn{6}{|c|}{ Estado civil } & \multirow{3}{*}{$\begin{array}{c}\text { Teste de } \\
\text { Welch } \\
\text { F }\end{array}$} \\
\hline & \multicolumn{2}{|c|}{ Solteiros(as) ( $n=496$ ) } & \multicolumn{2}{|c|}{$\begin{array}{l}\text { Casados(as) e união } \\
\text { de fato }(n=484)\end{array}$} & \multicolumn{2}{|c|}{$\begin{array}{c}\text { Separados(as), } \\
\text { divorciados(as) e } \\
\text { viúvos(as) ( } n=97 \text { ) }\end{array}$} & \\
\hline & $M$ & SD & $M$ & SD & $M$ & SD & \\
\hline Presentes & 167,80 & 145,07 & 326,57 & 324,05 & 276,22 & 245,91 & $53,60^{* * *}$ \\
\hline Bens & 113,81 & 146,99 & 217,58 & 216,41 & 210,67 & 265,49 & $41,02^{* * *}$ \\
\hline Total & 281,62 & 248,93 & 544,14 & 482,55 & 486,89 & 455,05 & $61,81^{* * * *}$ \\
\hline
\end{tabular}

Notas: ${ }^{* * *} p<0,001$

Fonte: Elaborada pelos autores.

O teste de Levene revelou a homogeneidade de variâncias, o que levou à aplicação da ANOVA (Tabela 6), verificando-se a existência de diferenças significativas no consumo estimado na época de Natal entre os indivíduos da religião cristã, os ateus e os das restantes religiões ( $p$ $<0,05)$. A magnitude das diferenças médias, segundo Pallant (2013), apresenta um tamanho de efeito pequeno $\left(\eta^{2}=0,01\right)$. Através da aplicação do teste de comparações múltiplas de Tukey, verificou-se a existência de diferenças significativas no consumo estimado na época de Natal entre os que têm religião (cristianismo e outras religiões) e os que não têm (ateísmo). Assim, os indivíduos que têm religião são os que mais estimam gastar na época de Natal, o que comprova empiricamente a Hipótese 9, corroborando com o estudo de Ribeiro (2018), que refere que a cultura cristã está ligada ao consumismo. Nessa época, o materialismo e o consumismo intensificam-se, algo considerado paradoxal com o espírito de Natal, uma vez que a religião cristã rejeita o materialismo (DEACY, 2016).

TABELA 6

Comparação do consumo estimado na época de natal entre os que possuem ou não familiar direto com menos de 16 anos

\begin{tabular}{|c|c|c|c|c|c|c|c|c|}
\hline \multirow{3}{*}{ Consumo } & \multicolumn{6}{|c|}{ Religião } & \multirow{3}{*}{$\begin{array}{c}\text { Teste } \\
\text { F }\end{array}$} & \multirow{3}{*}{$\begin{array}{l}\text { Tamanho } \\
\text { do efeito }\end{array}$} \\
\hline & \multicolumn{2}{|c|}{ Cristã (n= 938) } & \multicolumn{2}{|c|}{ Ateu $(n=103)$} & \multicolumn{2}{|c|}{ Outra $(n=36)$} & & \\
\hline & $M$ & SD & $M$ & SD & $M$ & $S D$ & & \\
\hline Presentes & 259,58 & 269,67 & 179,48 & 169,13 & 169,67 & 193,34 & $6,16^{* *}$ & 0,01 \\
\hline Bens & 174,23 & 198,06 & 122,95 & 140,00 & 169,47 & 333,97 & $3,07^{*}$ & 0,01 \\
\hline Total & 433,81 & 417,03 & 302,43 & 279,82 & 339,14 & 466,98 & $5,52^{* *}$ & 0,01 \\
\hline
\end{tabular}

Nota: ${ }^{* *} p<0,01,{ }^{*} p<0,05$.

Fonte: Elaborada pelos autores. 
O teste de Levene não revelou a homogeneidade de variâncias, o que levou à aplicação do teste de Welch (Tabela 7), verificando-se a existência de diferenças significativas no consumo estimado na época de Natal entre as diferentes regiões do país $(p<0,05)$. A partir do teste de comparações múltiplas de Games-Howell, verificaram-se diferenças significativas entre os indivíduos da região de Lisboa e do Alentejo $(p<0,05)$, o que suporta empiricamente a Hipótese 10, corroborando com os resultados dos estudos da consultoria Deloitte em 2018 e 2019. Note-se ainda que os indivíduos da região de Lisboa (distritos de Lisboa e Setúbal) e do Algarve (distrito de Faro) são os que estimam gastar mais na época de Natal.

\section{TABELA 7}

Comparação do consumo estimado na época de natal entre as diferentes regiões do país

\begin{tabular}{|c|c|c|c|c|}
\hline & & Presentes & Bens & Total \\
\hline \multirow{2}{*}{ Norte $(n=297)$} & $M$ & 257,45 & 163,12 & 420,57 \\
\hline & SD & 307,79 & 167,85 & 424,25 \\
\hline \multirow{2}{*}{ Centro $(n=482)$} & $M$ & 240,24 & 168,98 & 409,21 \\
\hline & SD & 222,94 & 206,17 & 375,65 \\
\hline \multirow{2}{*}{ Lisboa $(n=103)$} & $M$ & 324,08 & 221,35 & 545,43 \\
\hline & SD & 369,62 & 307,69 & 617,92 \\
\hline \multirow{2}{*}{ Alentejo $(n=164)$} & $M$ & 200,13 & 138,78 & 338,91 \\
\hline & SD & 164,81 & 127,07 & 273,71 \\
\hline \multirow{2}{*}{ Algarve $(n=31)$} & $M$ & 310,48 & 217,42 & 527,90 \\
\hline & SD & 240,63 & 209,25 & 407,66 \\
\hline Teste de Welch & $\mathrm{F}$ & $4,27^{* *}$ & $3,26^{*}$ & $4,70^{* * *}$ \\
\hline
\end{tabular}

Nota: "“"p $p<0,001, "$ " $p<0,01, " p<0,05$.

Fonte: Elaborada pelos autores.

Na Tabela 8, apresenta-se uma análise da importância dos diferentes momentos festivos da época natalícia, verificando-se que os inquiridos atribuem maior importância à noite de Natal, do dia 24 para o dia 25 de dezembro $(M=4,51, S D=0,87)$, e ao dia de Natal, 25 de dezembro $(M=4,34, S D=0,91)$. Atribui-se uma menor importância ao Dia de Reis, no dia 6 de janeiro $(M=2,79, S D=1,31)$, o que leva a concluir que os inquiridos vivenciam com maior intensidade as festas de Natal. 
TABELA 8

Análise da importância dos momentos festivos na época de natal

\begin{tabular}{|lcc|} 
& M & SD \\
\hline Noite de Natal (do dia 24 para o dia 25 de dezembro) & 4,51 & 0,87 \\
\hline Dia de Natal (dia 25 de dezembro) & 4,34 & 0,91 \\
\hline Passagem de ano (do dia 31 de dezembro para o dia 10 de janeiro) & 3,85 & 1,15 \\
\hline Entrada no novo ano (dia 10 de janeiro) & 3,70 & 1,16 \\
\hline Dia de Reis (dia 6 de janeiro) & 2,79 & 1,31 \\
\hline
\end{tabular}

Fonte: Elaborada pelos autores.

Da aplicação da correlação de Pearson, verificou-se a existência de relação estatisticamente significativa entre a importância dada ao Natal e o consumo estimado $(p<0,001)$. A correlação positiva $(r=0,12)$ significa que quanto mais importância os indivíduos dão à noite de Natal e ao dia de Natal, maiores serão os níveis de consumo estimado para essa época do ano.

\section{CONCLUSÕES}

O presente estudo apresentou como objetivo analisar o consumo estimado pelos portugueses na época de Natal. De acordo com os resultados obtidos, a grande maioria dos indivíduos (96,3\%) passa o Natal com a família. Verifica-se, também, que os 1.077 indivíduos que responderam ao questionário estimam gastar, em média, aproximadamente 418 euros na época de Natal, dos quais cerca de 249 euros estimados para gastos em presentes para oferecer, e cerca de 169 euros para gastos em bens de consumo. Tais valores situam-se abaixo da média europeia, que é de 461 euros. O fato de estar abaixo da média europeia não surpreende, pois o rendimento líquido das famílias em Portugal também é inferior a essa média.

Do presente estudo pode-se inferir que os portugueses estimam gastar mais em presentes para oferecer do que em bens de consumo. Quanto maior é o valor que estimam gastar em presentes para oferecer, maior é o valor estimado para gastar em bens de consumo.

Sobre a existência de relações entre o consumo e as variáveis sociodemográficas, pode-se inferir que são os homens que estimam gastar mais na época de Natal. O consumo estimado para essa época do ano aumenta com a idade, o número de elementos do agregado familiar, o nível de escolaridade e o rendimento mensal do agregado familiar. Os indivíduos casados ou que vivem em união de fato são os que estimam gastar mais. Em termos de região do país, verificou-se que os indivíduos da região de Lisboa e do Algarve são os que estimam maiores gastos. Tal como seria de esperar, o fato de possuir um familiar direto com menos de 16 anos, e, consequentemente, a compra de um presente para lhe oferecer, leva os indivíduos a estimar maiores valores a gastar no Natal. Embora as conclusões anteriores fossem mais ou menos esperadas, estes são assuntos nunca estudados na gestão, na administração e no marketing em Portugal. O consumo está relacionado, em termos de economia, com o rendimento disponível das famílias, sendo o rendimento das famílias em Portugal inferior à média europeia. Lisboa é a região do país com maior rendimento, e o Algarve a região de férias do país, por excelência. 
No que concerne ao credo, são os indivíduos que têm religião os que mais estimam gastar na época de Natal, comparativamente com os que não têm religião. Como referem Cruz (2013) e Roque (2013), o Natal batizou uma festa pagã, e o secretismo e o casamento da espiritualidade e mundanidade mantiveram-se ao longo do tempo. Assim, essa data não é só religiosa, mas também propícia ao convívio familiar, ao consumo e ao materialismo, hoje mais observável. Isso se deve às férias escolares e familiares, que muitas famílias fazem, por ser um período de maior convívio.

O artigo contribui para conhecer melhor como se comporta o povo português relativamente ao consumo no Natal, percebendo-se algum materialismo em seus atos. Também permite perceber que, apesar do grau de consumismo e materialismo do povo português nessa data festiva, apenas $0,3 \%$ dos indivíduos apresenta tendência para o endividamento em função das comemorações natalinas.

Em suma, os portugueses vivenciam, com grande intensidade, as festas de Natal quando comparadas com a passagem do ano e com o Dia de Reis, o que significa que quanto mais importância os indivíduos dão à época de Natal, maior é o nível de consumo estimado para gastar nessa época.

Considerando as caraterísticas do trabalho, algumas limitações foram observadas. Assim, não existem muitos trabalhos de investigação sobre o Natal, especialmente em Portugal, o que torna este trabalho ainda exploratório, não sendo possível a comparação de alguns aspetos abordados com a literatura existente, o que empobrece a discussão.

Futuramente, pretende-se averiguar a importância da simbologia da festividade e sua influência no consumismo na época específica do Natal. Pretende-se também investigar que tipo de prendas mais se oferecem no natal, e qual a importância de oferecer presentes. $\mathrm{O}$ estudo realizado na presente investigação pode ajudar acadêmicos, investigadores e profissionais a compreender melhor o consumismo da população portuguesa na época de Natal. 


\section{REFERÊNCIAS}

ARNOULD, E. et al. Consumer culture theory: development, critique, application and prospects. Foundations and Trends ${ }^{\circledast}$ in Marketing, v. 12, n. 2, p. 80-165, 2019.

BARR, N. Economics of the welfare state. Oxford: Oxford University Press USA, 2020.

BATINGA, G. L.; PINTO, M. R.; RESENDE, S. P. Natal, consumo e materialismo: uma análise discursiva de cartas infantis de Natal. Revista Brasileira de Gestão de Negócios, v. 19, n. 66, p. 557-573, 2017.

BRIDA, J. G.; DISEGNA, M.; OSTI, L. Visitors' expenditure behavior at cultural events: the case of Christmas markets. Tourism Economics, v. 19, n. 5, p. 1173-1196, 2013.

BRIDA, J. G.; MELEDDU, M.; TOKARCHUK, O. Use value of cultural events: the case of the Christmas markets. Tourism Management, v. 59, p. 67-75, abr. 2017.

BURROUGHS, S. Consumer capitalist Christmas: how participation in Christmas frames us as religious subjects. (Religion: Student Scholarship \& Creative Works, 8). Illinois: Augustana College, 2019. Disponível em: <https://digitalcommons.augustana.edu/relgstudent/8>. Acesso em: 10 dez. 2020.

CLARKE, P. A measure for Christmas spirit. Journal of Consumer Marketing, v. 24, n. 1, p. 8-17, 2007.

CRUZ, M. B. O desencantamento do Natal. Gaudium Sciendi, n. 5, p. 78-90, 2013.

CUNHA, M., TAVARES, F. O., DURÃO, M. Como as marcas de moda de luxo se comunicam pelas redes sociais: um contributo das redes sociais on-line nas relações B2C. Revista Brasileira de Pesquisas de Marketing, Opinião e Mídia, v. 12, n. 1, p. 64-80, 2019.

DEACY, C. Christmas as religion: rethinking Santa, the secular, and the sacred. Oxford: Oxford University Press, 2016.

DELOITTE. Portugueses esperam gastar $314 €$ nas compras de Natal, $63 €$ abaixo da média europeia. Estudo de Natal 2018. Deloitte, Lisboa, 14 nov. 2018. Disponível em: <https://www2.deloitte.com/pt/pt/ pages/about-deloitte/articles/estudo-de-natal-2018-comunicado.html>. Acesso em: 10 dez. 2020.

DELOITTE. The magic of Christmas: Christmas Survey 2019. Portuguese results. London: Deloitte, 2019. Disponível em: <https://www2.deloitte.com/content/dam/Deloitte/pt/Documents/consumerbusiness/estudos-natal/EstudoNatal2019/XmasSurvey2019_Portugal.pdf>. Acesso em: 10 dez. 2020.

DYBLE, M.; VAN LEEUWEN, A. J.; DUNBAR, R. I. M. Gender differences in Christmas gift-giving. Evolutionary Behavioral Sciences, v. 9, n. 2, p. 140, 2015.

GANASSALI, S. Status of brands in children's consumption: what letters to Santa posted on La Poste website tell us. Psychology \& Marketing, v. 36, n. 1, p. 5-14, 2019.

HAIR, J. F. et al. Multivariate data analysis (7th ed.). Edinburgh: Pearson, 2014.

MARÔCO, J. Análise estatística com o SPSS Statistics 25 (7th ed.). Lisboa, Portugal: Report Number, 2018.

MILLER, D. Christmas: an anthropological lens. Journal of Ethnographic Theory, v. 7, n. 3, p. 409-442, 2017.

PALLANT, J. SPSS survival manual: a step by step guide to data analysis using SPSS for Windows (5th ed.). Maidenhead: Open University Press, 2013. 
PESTANA, M. H.; GAGEIRO J. N. Análise de dados em ciências sociais: a complementaridade do SPSS (6. ed.). Lisboa: Sílabo, 2014.

PORDATA. Rendimento médio disponível das famílias. Lisboa: Fundação Francisco Manuel dos Santos, 2020. Disponível em: <https://www.pordata.pt/Portugal/ Rendimento+m\%C3\%A9dio+dispon\%C3\%ADvel+das+fam\%C3\%ADlias-2098>. Acesso em: 10 dez. 2020.

RIBEIRO, S. R. A cultura consumista e a juventude contemporânea: as contribuições do cristianismo na formação da identidade do adolescente na cultura consumista. Bona Conscientia, v. 1, n. 1, p. 188-202, 2018.

ROBINOT, E.; ERTZ, M.; DURIF, F. Jingle bells or 'green' bells? The impact of socially responsible consumption principles upon consumer behaviour at Christmas time. International Journal of Consumer Studies, v. 41, n. 6, p. 605-617, 2017.

ROQUE, M. I. O Menino de Belém: da festa do Natal à iconografia da Natividade e da adoração. Gaudium Sciendi, n. 5, 104-126, 2013.

SCHUSTER, M.; DIAS, V.; BATTISTELLA, L. F. Validação e investigação da relação entre comportamento compulsivo de compra e consumismo. Revista de Administração FACES Journal, v. 15, n. 3, p. 51-68, 2016.

SIMÕES, C. F.; AMARAL, S. C. A relação entre a escolaridade e a pobreza: uma análise das políticas para democratização do acesso ao ensino superior no Brasil. Revista Brasileira de Ensino Superior, v. 4, n. 2, p. 21-43, 2018.

TAVARES, F. O.; PACHECO, L. M.; SOUSA, P. F. Análise dos fatores de atratividade dos shoppings centers no Porto, Portugal. Revista de Negócios, v. 19, n. 4, p. 84-102.

\section{EULÁLIA SANTOS}

ORCID: https://orcid.org/0000-0001-8069-2657

Professor na Escola Superior de Tecnologia e Gestão (ESTG) do Politécnico de Leiria.

E-mail: eulalia.santos@ipleiria.pt

\section{FERNANDO OLIVEIRA TAVARES}

ORCID: http://orcid.org/0000-0002-9672-8770

Professor no Instituto Superior de Ciências Empresariais e do Turismo (ISCET). E-mail: ftavares@iscet.pt 